\title{
inorganics
}

ISSN 2304-6740

www.mdpi.com/journal/inorganics

Article

\section{Dinuclear Lanthanide (III) Coordination Polymers in a Domino Reaction}

Edward Loukopoulos ${ }^{1}$, Kieran Griffiths ${ }^{1}$, Geoffrey R. Akien ${ }^{2, *}$, Nikolaos Kourkoumelis ${ }^{3}$, Alaa Abdul-Sada ${ }^{1}$ and George E. Kostakis ${ }^{1, *}$

1 Department of Chemistry, School of Life Sciences, University of Sussex, Brighton BN1 9QJ, UK; E-Mails: E.Loukopoulos@sussex.ac.uk (E.L.); K.Griffiths@sussex.ac.uk (K.G.); a.abdul-sada@sussex.ac.uk (A.A.-S.)

2 Department of Chemistry, Lancaster University, Lancaster LA1 4YB, UK

3 Department of Medical Physics, School of Health Sciences, University of Ioannina, 45110 Ioannina, Greece; E-Mail: nkourkou@cc.uoi.gr

* Authors to whom correspondence should be addressed; E-Mails: g.akien@lancaster.ac.uk (G.R.A.); g.kostakis@sussex.ac.uk (G.E.K.); Tel.: +44-1273-877-339 (G.E.K); +44-1524-593-790 (G.R.A.); Fax: +44-1273-876-687 (G.E.K.).

Academic Editors: Stephen Mansell and Steve Liddle

Received: 13 October 2015 / Accepted: 29 October 2015 / Published: 6 November 2015

\begin{abstract}
A systematic study was performed to further optimise the catalytic room-temperature synthesis of trans-4,5-diaminocyclopent-2-enones from 2-furaldehyde and primary or secondary amines under a non-inert atmosphere. For this purpose, a series of dinuclear lanthanide (III) coordination polymers were synthesised using a dianionic Schiff base and their catalytic activities were investigated.
\end{abstract}

Keywords: coordination polymers; lanthanide; single crystal; ${ }^{89} \mathrm{Y}-\mathrm{NMR}$; catalysis; domino reaction

\section{Introduction}

The interest in lanthanide (4f) coordination chemistry has grown considerably during the last decade. From a synthetic point of view, the high coordination number that $4 \mathrm{f}$ elements favour and the steric demand of the organic ligands used govern the size and the nuclearity of the resulting coordination 
clusters (CCs) [1]. Unprecedented and aesthetically pleasant structures, such as the "bottlebrush" Ln19 [2], the peptoid-based $\operatorname{Ln}_{15}$ [3], the two dimensional (2D) coordination polymers based on Ln36 units [4], and the world record four-shell Keplerates Ln104 [5], have been recently reported. However, the popularity of $4 \mathrm{f}$ coordination chemistry is being exploited rapidly due to their association in diverse research areas, such as molecular magnetism [6,7], molecular bioimaging [8], optics [9,10], catalysis [11-13], and the possibility to simultaneously exhibit more than one property [14-18].

Schiff base ligands, due to their low cost, ease of access and several coordination modes, have received a large amount of attention, especially in the last five years, and thus have been widely employed in the synthesis of polynuclear CCs [19-37]. Using (E)-2-(2-hydroxy-3-methoxybenzylideneamino)phenol $\left(\mathrm{H}_{2} \mathrm{~L} 1\right.$, Scheme 1 left), we recently initiated a project towards the synthesis of $3 \mathrm{~d} / 4 \mathrm{f} \mathrm{CCs}$ that would display catalytic properties [38]. We showed that three 3d/Dy(III) CCs remain intact into solution and display homogeneous catalytic behaviour in the room-temperature synthesis of trans-4,5diaminocyclopent-2-enones from 2-furaldehyde and primary or secondary amines under a non-inert atmosphere [38]. Our studies indicated that the catalytic activity is owed to the Dy(III) ion, highly dependent on its coordination environment, and required an order of magnitude less loading in comparison with the parent catalyst Dy(OTf) 3 [39].

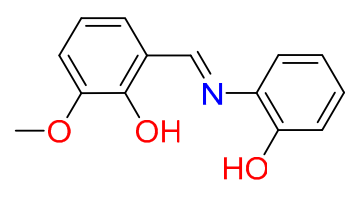

$\mathrm{H}_{2} \mathrm{~L} 1$

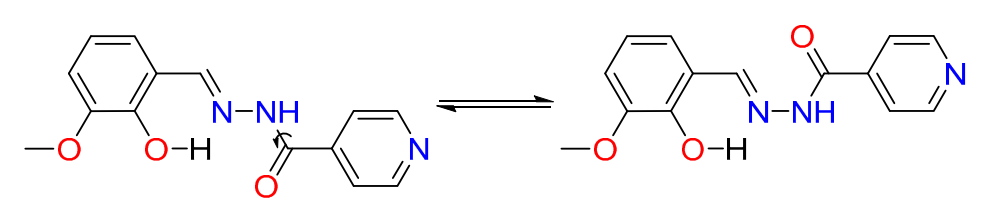

$\mathrm{H}_{2} \mathrm{~L} 2$

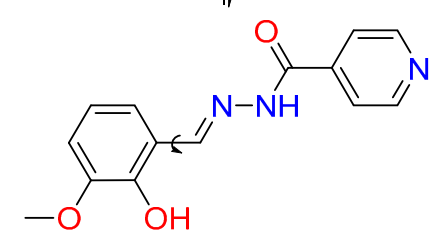

Scheme 1. The organic ligands discussed in the text. In DMSO- $d_{6}$, ligand $\mathrm{H}_{2} \mathrm{~L} 2$ exhibits two rotamers in an 11.5:1 ratio with observable NOESY exchange peaks between the two, and their identity confirmed by ${ }^{15} \mathrm{~N}-\mathrm{HMBC}$ experiments giving ${ }^{1} \mathrm{~J}_{\mathrm{NH}}$ of 93.6 and $91.6 \mathrm{~Hz}$ for the major and minor amide protons, respectively. Since there are two plausible bonds with restricted rotation it is not possible to unambiguously assign their identities. Nevertheless the distinctly different chemical shifts for the phenol OH's (10.71 ppm for the major and 9.43 for the minor), imply that one of the two rotamers possesses an intramolecular H-bond.

With this in mind, we decided to employ a pure $4 \mathrm{f} \mathrm{CC}$ as catalyst in the aforementioned domino reaction. The employment of $\mathrm{H}_{2} \mathrm{~L} 1$ in $4 \mathrm{f}$ chemistry affords tetranuclear compounds that possess a defect dicubane motif [26], but the coordination sites of all four $4 \mathrm{f}$ ions are occupied by the organic moieties and most importantly do not retain their structure into solution. Therefore, we addressed to employ another Schiff base ligand that exhibits more steric demands and thus we concluded that $(E)-N^{\prime}$-(2-hydroxy-3-methoxybenzylidene)isonicotinohydrazide $\left(\mathrm{H}_{2} \mathrm{~L} 2\right.$, Scheme 1 right) can serve this purpose. This ligand has been used for the synthesis of a series of Mn compounds [40] as well two pseudopolymophic [41-43] compounds formulated as $\left[\mathrm{Dy}_{2}(\mathrm{~L} 2)_{2}\left(\mathrm{NO}_{3}\right)_{2}(\mathrm{MeOH})_{2}\right]$ and 
[Dy $\left.2(\mathrm{~L} 2)_{2}\left(\mathrm{NO}_{3}\right)_{2}(\mathrm{MeOH})_{2}\right] \cdot \mathrm{MeCN}$ (1-Dy MeCN) [44]. Interestingly, compound 1-Dy forms a 2D network via the pyridine group and each Dy centre coordinates to one solvent molecule (Figure 1).

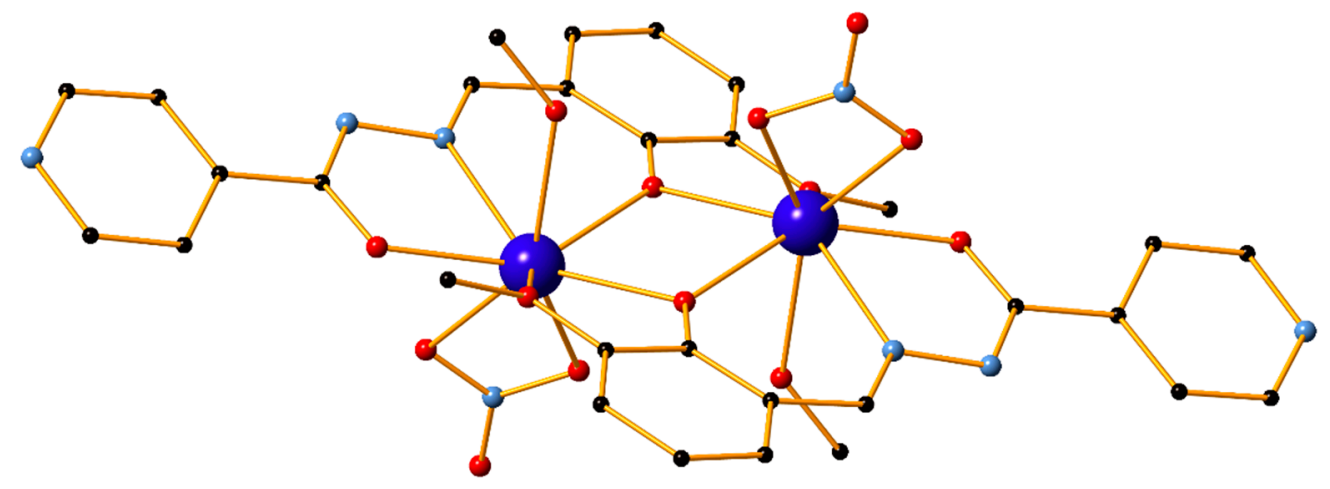

Figure 1. The structure of 1-Dy as reported by Murugesu et al. [44]. $\mathrm{H}$ atoms and solvent molecules are omitted for clarity. Colour code Dy (purple), C (black), N (blue), O (red).

Being motivated by our initial catalytic results [38], in this work, we decided to investigate the possibility of using 1-Dy as catalyst in the aforementioned domino reaction. Moreover, having in mind that (a) the catalytic efficiency is highly dependent on the coordination environment of the metal centre, and (b) the imperative to seek lower cost materials, we decided to perform a systematic study incorporating other lanthanides and thus we present herein the synthesis and characterization of the following compounds $\left[\mathrm{Dy}_{2}(\mathrm{~L} 2)_{2}\left(\mathrm{NO}_{3}\right)_{2}(\mathrm{MeOH})_{2}\right] \cdot \mathrm{MeCN}(\mathbf{1}-\mathbf{D y} \cdot \mathrm{MeCN})$, $\left[\mathrm{Gd}_{2}(\mathrm{~L} 2)_{2}\left(\mathrm{NO}_{3}\right)_{2}(\mathrm{MeOH})_{2}\right] \cdot \mathrm{MeCN} \cdot \mathrm{MeOH}(\mathbf{1 - G d}),\left[\mathrm{Y}_{2}(\mathrm{~L} 2)_{2}\left(\mathrm{NO}_{3}\right)_{2}(\mathrm{EtOH})_{0.32}\left(\mathrm{H}_{2} \mathrm{O}\right)_{0.68}\right] \cdot 0.68 \mathrm{EtOH}(\mathbf{1 - Y})$, $\left[\mathrm{Dy}_{2}(\mathrm{HL} 2)_{3} \mathrm{Cl}_{2}\right] \cdot \mathrm{Cl} \cdot\left(\mathrm{H}_{2} \mathrm{O}\right)_{6} \cdot(\mathrm{MeOH})(\mathbf{2}-\mathrm{Dy}), \quad\left[\mathrm{Gd}_{2}(\mathrm{HL} 2)_{3} \mathrm{Cl}_{2}\right] \cdot \mathrm{Cl} \cdot\left(\mathrm{H}_{2} \mathrm{O}\right)_{6} \quad(\mathbf{2}-\mathbf{G d}), \quad\left[\mathrm{Y}_{2}(\mathrm{HL} 2)_{3} \mathrm{Cl} 2\right] \cdot \mathrm{Cl} \cdot$ $\left(\mathrm{H}_{2} \mathrm{O}\right)_{6} \cdot(\mathrm{MeOH})(\mathbf{2}-\mathrm{Y})$, [Dy(HL2)(NO3 $\left.)_{2}(\mathrm{MeOH})_{2}\right](\mathbf{3}-\mathrm{Dy})$ and $\left[\mathrm{Y}(\mathrm{HL} 2)_{2}(\mathrm{MeOH})_{2}\right] \cdot \mathrm{Cl} \cdot \mathrm{MeCN}(\mathbf{4}-\mathbf{Y})$. The catalytic performance of compounds $\mathbf{1 - Y}$ and $\mathbf{2 - Y}$ is further monitored by solution NMR studies $\left({ }^{1} \mathrm{H}\right.$ and $\left.{ }^{89} \mathrm{Y} \mathrm{NMR}\right)$.

\section{Results and Discussion}

Having chosen to study this metal:ligand system for catalytic purposes, we initiated our study by employing the dinuclear Dy2 complex (1-Dy), which was reported by Murugesu et al. [44]. We then expanded the system by employing a series of lanthanides, $\mathrm{Ln}\left(\mathrm{NO}_{3}\right)_{3}$ and $\mathrm{LnCl}_{3}$, while keeping the synthetic method similar, then exploring their catalytic potential. This approach was adopted for the following reasons: (a) this would account for a fully systematic study and a better understanding of the role that the lanthanide and the anion play during the catalytic process; (b) the proposed synthetic method was easy and also ideal for affording high yields of the product; (c) while the $\mathrm{Ln}\left(\mathrm{NO}_{3}\right)_{3}$ sources are generally cheaper, affording the products using $\mathrm{LnCl}_{3}$ sources and the aforementioned synthetic method has the least cost overall.

As such, in our efforts to synthesise an analogue of 1-Dy using $\mathrm{DyCl}_{3}$ as the metal source and a similar synthetic method, we obtained compound 2-Dy. The compound is also a Dy (III) dimer (Figure 2A) which crystallises in the monoclinic $\mathrm{P} 21 / \mathrm{n}$ space group $(Z=4)$. The structure contains three chlorine atoms, out of which two act as terminal ligands, and three ligand molecules. Despite the unsatisfactory crystallographic data, TGA analysis also confirms the presence of one methanol and six water molecules 
in the lattice. Each of the organic ligands is only deprotonated in the phenoxide group (HL2 ${ }^{-}$) to account for the total charge balance. This is further confirmed by the related $\mathrm{C}-\mathrm{O}$ distances (Table $\mathrm{S} 1$ ), which are indicative of a double bond. Dy1 is bonded to a $\left\{\mathrm{ClN}_{2} \mathrm{O} 6\right\}$ coordination, including a pyridyl $\mathrm{N}$ atom of a neighbouring HL2 ${ }^{-}$ligand (Scheme S1). As a result, the compound forms a one-dimensional zig-zag network which extends to the $a 0 c$ plane (Figure 2B). Using SHAPE software [45], the geometry of Dy1 may be best described as a tridiminished icosahedron (J63). Dy2 is also coordinated to nine atoms in a $\left\{\mathrm{ClN}_{2} \mathrm{O} 6\right\}$ environment and possesses a muffin geometry. The two metal centres are bridged by the phenoxide oxygen atoms of all three ligands, with the Dy-O-Dy angles ranging from 95.92(17) ${ }^{\circ}$ to $99.73(19)^{\circ}$. Out of the respective Dy-O distances, Dy1-O6 was the longest at 2.570(5) $\AA$, while Dy1-O8 was the shortest at 2.277(4) $\AA$. Similarly, for the respective Dy-N distances, the mean Dy1-N3 distance was the longest at 2.692(6) $\AA$, while Dy1-N7 was the shortest at 2.495(7) $\AA$. Selected bond lengths and angles are given in Table $\mathrm{S} 2$.

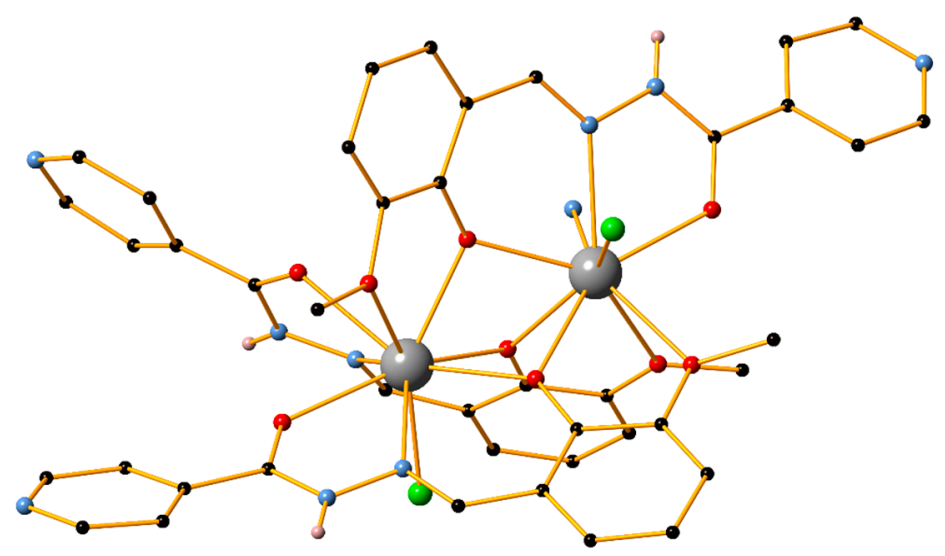

(A)

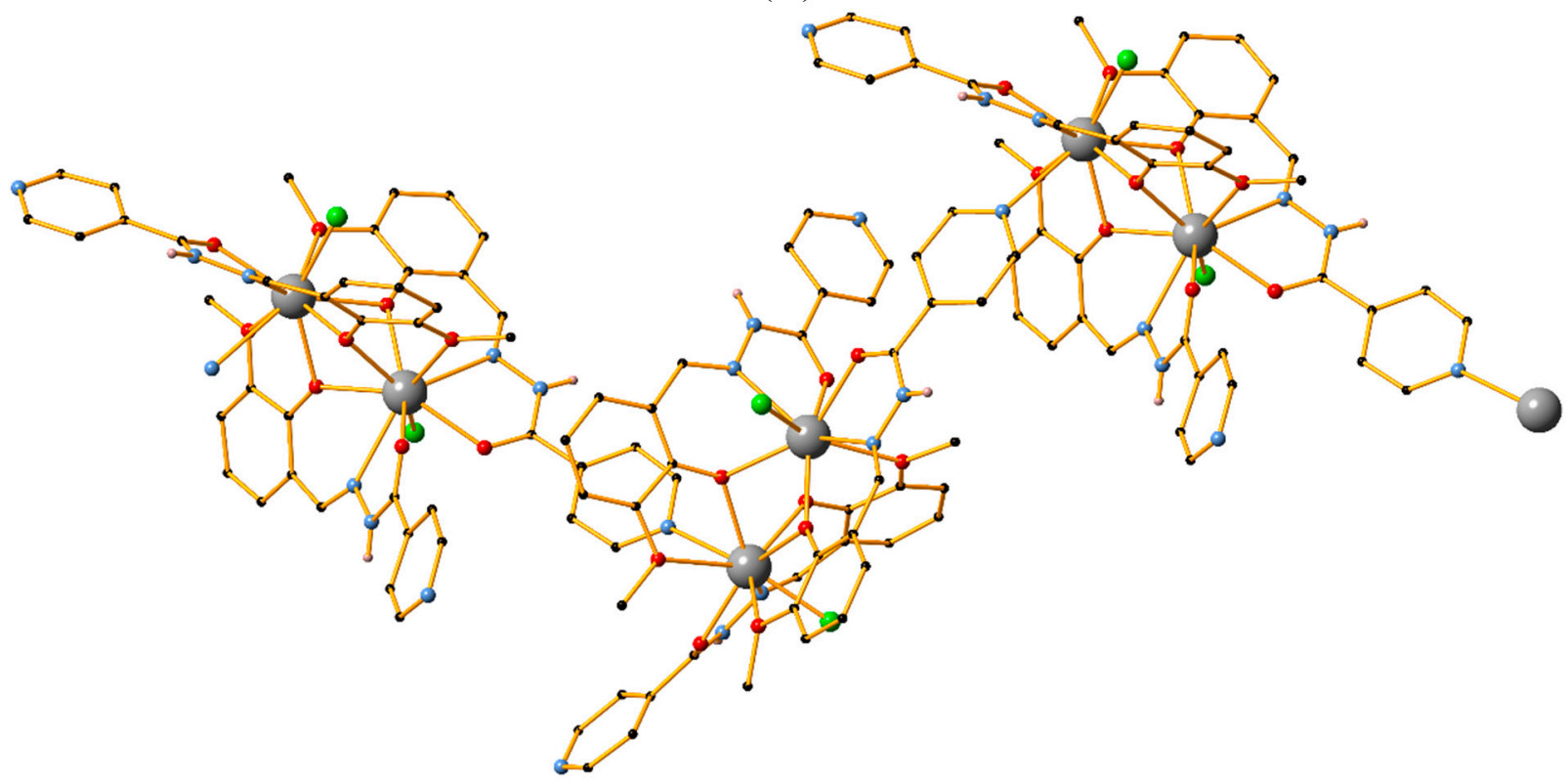

(B)

Figure 2. (A) The structure of compounds 2-Dy, 2-Gd and 2-Y. X = Dy, Gd, Y; (B) Part of the 1D framework of compounds 2-Dy, 2-Gd and 2-Y. Certain $\mathrm{H}$ atoms and all solvent molecules are omitted for clarity. Colour code $\mathrm{X}$ (grey), $\mathrm{Cl}$ (green), $\mathrm{C}$ (black), $\mathrm{N}$ (light blue), $\mathrm{O}$ (red). 
We then attempted to test the catalytic properties of 1-Dy and 2-Dy to determine whether Dy(III) behaves in a similar fashion to the reported Dy(OTf) 3 [39] and our initial results [38]. In the following protocol, the reactions were performed in acetonitrile in air, at room temperature using variable catalytic loadings ranging from $10 \%-1 \%$. Before going into detail, it is crucial to mention that a solubility test was carried out to identify the behaviour of 1-Dy and 2-Dy in $\mathrm{CH}_{3} \mathrm{CN}$ solution; despite the polymeric character of 1-Dy and 2-Dy, 2D and 1D, respectively, both compounds are slightly soluble in $\mathrm{CH}_{3} \mathrm{CN}$ solutions and, thus, the catalytic process takes place in a homogeneous phase. Under these conditions, the reaction between 2-furaldehyde and morpholine led to the quantitative formation of $(4 S, 5 R)$ dimorpholinocyclopent-2-enone at 10\% loading with both complexes (Table 1, Entries $1+5$ ). With the reduction of loading there are small decreases in yields, however even the lowest of these is acceptable. Noticeably, the nitrate analogue 1-Dy performs marginally better than the chloride analogue (2-Dy) $(6 \%-7 \%)$ at $5 \%$ and $2.5 \%$ loading (Table 1 , Entries $2+3$ and $6+7$, respectively).

Our next step was to test the efficiency of lanthanides lighter than Dy. Compound 1-Gd was synthesised in an analogous manner and was confirmed to be pseudopolymorphic [41-43] to 1-Dy through IR and thermal studies. As such, it is a dinuclear $\mathrm{Gd}_{2}$ complex containing the same $\mathrm{Ln}_{2}(\mathrm{HL} 2)_{2}\left(\mathrm{NO}_{3}\right)_{2}(\mathrm{MeOH})_{2}$ core and extending to two dimensions through the pyridine group. In our efforts to synthesise the chloride-based Gd analogue, we obtained compound 2-Gd. X-ray and thermal studies, as well as IR (Figure S1) reveal that it is a dinuclear $\mathrm{Gd}_{2}$ complex, pseudopolymorphic to 2-Dy and therefore also a 1D coordination polymer. As shown in Table 1, Entries 9 and 10, both Gd(III) analogues show a reduced activity in comparison to the Dy(III) compounds.

We then proceeded to explore the attributes of $\mathrm{Y}$, which has similar ionic radius to Dy. We first employed $\mathrm{Y}\left(\mathrm{NO}_{3}\right)_{3}$ as the metal source to obtain compound 1-Y. The complex forms a $2 \mathrm{D}$ network via the pyridine group and each Y centre coordinates to one solvent molecule (Figure S2). The crystal structure was found to be pseudopolymorphic to 1-Dy and as a result it will not be described in further detail. However, its measured diffusion coefficient in DMSO- $d_{6}$ was of a similar order of magnitude to that of $2-Y\left(1.98\right.$ versus $\left.2.15 \times 10^{-10} \mathrm{~m}^{2} \cdot \mathrm{s}^{-1}\right)$, so it is assumed to dissociate on dissolution. The imine proton was broadened to an extent consistent with a ${ }^{3} J_{\mathrm{YH}} 0.9 \mathrm{~Hz}$ doublet (lineshape fitting), and this narrowed significantly on the application of ${ }^{89} \mathrm{Y}$-decoupling. While it was possible to observe a strong 3-bond correlation between the imine $\mathrm{H}$ and the $\mathrm{Y}$ centre (92 ppm) via ${ }^{89} \mathrm{Y}-\mathrm{HMBC}$ (S/N 275 in $20 \mathrm{~min}$ experiment time, optimised for $J_{\mathrm{YH}} 2 \mathrm{~Hz}$ ), it was not possible to detect any 3-bond correlation between the methoxy and Y atom, even with many more scans. It is possible that this is a normal feature of such complexes, but it is certainly suggestive of the methoxy being uncoordinated in the solution state.

Compound 2-Y was synthesised using $\mathrm{YCl}_{3}$ and the same synthetic method as above for 2-Dy. IR and thermal studies confirm that the compound is isostructural to 2-Dy and contains the same $\mathrm{Ln}_{2}\left(\mathrm{HL}_{2}\right)_{3} \mathrm{Cl}_{2}$ core. Similarly as with $\mathbf{1 - Y}$, it was possible to measure a strong 3-bond correlation between the imine $\mathrm{H}$ and $\mathrm{Y}$ (111 ppm), but again, no correlation to the methoxy group. The ${ }^{15} \mathrm{~N}-\mathrm{HMBC}$ correlation between the imine $\mathrm{H}$ and the hydrazide $\mathrm{N}$ (321.7 ppm) was also intense enough that it was possible to acquire a highly-aliased high-resolution spectrum sufficient to determine the first ever ${ }^{1} J_{\mathrm{YN}}$ coupling of $9.1 \mathrm{~Hz}$. It was not possible to do this for $\mathbf{1 - Y}$, at the same concentration $(20 \mathrm{mg} / 0.5 \mathrm{~mL})$. Due to the similarities of the ${ }^{1} \mathrm{H}$ and ${ }^{13} \mathrm{C}$ spectra for $\mathbf{1 - Y}$ and $\mathbf{2 - Y}$, a mixture of $9.9 \mathrm{mg} \mathbf{1 - Y}$ and $5.8 \mathrm{mg}$ 2-Y were mixed and dissolved in DMSO- $d 6$. Only one set of peaks could be observed by ${ }^{1} \mathrm{H} \mathrm{NMR}$, and it was not possible to measure any correlations by ${ }^{89} \mathrm{Y}-\mathrm{HMBC}$ at all. A plausible explanation is due to 
intermediate exchange between the two species in solution, but since the ${ }^{1} \mathrm{H}$ and ${ }^{13} \mathrm{C}$ chemical shifts are so similar, there is negligible broadening in their respective $1 \mathrm{D}$ spectra. However, the ${ }^{13} \mathrm{C}$ resonances with the largest differences between $\mathbf{1 - Y}$ and $\mathbf{2 - Y}(\Delta 0.55 \mathrm{ppm})$ was the quaternary carbon adjacent to the imine, and these were significantly broadened.

Regarding their catalytic activity, the efficiency of the $\mathrm{Y}_{2}$ analogues (Table 1, Entries 11-16), with either chloride or nitrate ion, out-perform any all counterpart Ln(III) analogues including Dy(III). These analogues retain good catalytic activity when the loading is decreased from $2.5 \%$ to $1 \%$ with yields above $89 \%$ (entries 12 and 15), however decrease significantly when lowered to $0.5 \%$. The Dy(III)and Y(III) ions have a similar ionic radius, which could relate to comparable activities, with 4 f orbital effects influencing the difference.

Table 1. Comparison of catalytic activity for compounds 1-Dy, 2-Dy, 1-Gd, 2-Gd, 1-Y and 2-Y a .

\begin{tabular}{|c|c|c|c|c|}
\hline Entry & Catalyst & Loading/\% & Time $/ \mathrm{h}$ & Yield $/ \%$ \\
\hline 1 & 1-Dy & 10 & 2 & 100 \\
\hline 2 & 1-Dy & 5 & 2 & 96 \\
\hline 3 & 1-Dy & 2.5 & 2 & 95 \\
\hline 4 & 1-Dy & 1 & 2 & 80 \\
\hline 5 & 2-Dy & 10 & 2 & 100 \\
\hline 6 & 2-Dy & 5 & 2 & 90 \\
\hline 7 & 2-Dy & 2.5 & 2 & 88 \\
\hline 8 & 2-Dy & 1 & 2 & 79 \\
\hline 9 & 1-Gd & 2.5 & 2 & 80 \\
\hline 10 & 2-Gd & 2.5 & 2 & 54 \\
\hline 11 & $1-Y$ & 2.5 & 2 & 100 \\
\hline 12 & $1-Y$ & 1 & 2 & 89 \\
\hline 13 & $1-Y$ & 0.5 & 2 & 68 \\
\hline 14 & $2-Y$ & 2.5 & 2 & 100 \\
\hline 15 & $2-Y$ & 1 & 2 & 85 \\
\hline 16 & $2-\mathrm{Y}$ & 0.5 & 2 & 38 \\
\hline
\end{tabular}

a Reaction conditions: morpholine, $1 \mathrm{mmol}$; 2-furaldehyde, $0.5 \mathrm{mmol}$; 4A MS, $100 \mathrm{mg}$; anhydrous MeCN, $4 \mathrm{~mL}$; room temperature; ${ }^{b}$ Catalyst loading calculated per equivalent of $\mathrm{Ln}^{\mathrm{III}}$. Yields calculated by ${ }^{1} \mathrm{H}$ NMR spectroscopy.

A closer look in the ESI-MS studies (Section 2.1) reveals that the core in all aforementioned compounds behave similarly in solution. All complexes exhibit a peak that corresponds to the $\left[\mathrm{Ln}(\mathrm{L})(\mathrm{MeOH})_{2}\right]^{1+}$ monocationic fragment, indicating that this species contributes to the catalysis. Having this in mind, in order to better study the system we attempted to synthesise a mononuclear analogue, focusing on Dy(III) and Y(III) compounds which provided the best catalytic yields. As a result, we obtained complexes 3-Dy and 4-Y. The former is a Dy(III) monomer, with two molecules in the asymmetric unit $(Z=4)$. The monomer consists of two nitrate and two methanol molecules that act as 
terminal ligands, as well as one organic ligand molecule which is deprotonated only in the phenoxide group (Figure $3 \mathrm{~A}$ ). Each metal centre possesses a $\left\{\mathrm{N}_{1} \mathrm{O}_{8}\right\}$ coordination environment and their geometry may be best described as a capped square antiprism (J10) [45]. The compound crystallises in the triclinic $P \overline{1}$ space group and is stabilised by strong $\mathrm{O}-\mathrm{H} \cdots \mathrm{O}, \mathrm{N}-\mathrm{H} \cdots \mathrm{O}$ and $\mathrm{O}-\mathrm{H} \cdots \mathrm{N}$ hydrogen bonds through participation of the ligated methanols, the nitrate anions and the pyridine nitrogen atom (Table S5). Table S3 contains selected bond distances for this structure. 4-Y is an Y(III) monomer which crystallises in the monoclinic $\mathrm{P} 21 / \mathrm{c}$ space group $(Z=4)$. The structure consists of two ligand molecules, two methanol solvent molecules which act as terminal ligands, one acetonitrile solvent molecule in the lattice and one chlorine counter ion (Figure 3B). The organic ligands are once again only deprotonated in the phenoxide group, as evidenced by the $\mathrm{C}-\mathrm{O}$ bond distances (Table $\mathrm{S} 1$ ). The metal centre has a $\left\{\mathrm{N}_{2} \mathrm{O}_{6}\right\}$ coordination environment and its geometry may be best described as triangular dodecahedron [45]. Each ligand coordinates to the $\mathrm{Y}$ (III) centre through the pocket which consists of the phenoxide, imine and carbonyl atoms. The $\mathrm{Y}-\mathrm{O}$ distances range from 2.210(2) $\AA$ to 2.402(2) $\AA$, while the $\mathrm{Y}-\mathrm{N}$ distances are longer, ranging from 2.482(3) $\AA$ to 2.509(3) $\AA$. Selected bond lengths may be found in Table S4. The structure is further stabilised by various strong intermolecular $\mathrm{O}-\mathrm{H} \cdots \mathrm{N}$ and intramolecular $\mathrm{N}-\mathrm{H} \cdots \mathrm{Cl}$ hydrogen bonds, which also account for the formation of a two-dimensional architecture at a supramolecular level. Characteristics for these bonds may be found in Table S6.

The 1-Y analogue, which demonstrated the highest efficiency of all the characterised compounds (Table 1, Entries 11 and 12) was chosen to optimise and explore the scope of this for a variety of secondary and primary amines as substrates. Due to $\mathbf{1 - Y}$ showing a decrease in activity from quantitative, when loadings are reduced to $1 \%$ (Table 1, Entry 12), which is not observed in the previously reported procedure [38], a higher loading of catalyst (2.5\%) was employed in an attempt to reduce the reaction time for quantitative conversion.

In all cases the reaction proceeded to the expected products (Table 2) and demonstrated the same ability as previously reported catalyst [38] to form deprotonated Stenhouse salts from the primary amine substrates. The increased \% loading of catalyst, in $8 \mathrm{~h}$ (From $16 \mathrm{~h}$ ) with primary amine substrates affords a higher yield of Stenhouse salt products (Table 2, 5a-5b) than previously reported conditions. The time for secondary amine substrate conversion was reduced from 16 to $4 \mathrm{~h}$, with similar conversion percents for products $\mathbf{5 a}, \mathbf{5 b}$ and $\mathbf{5 c}$. However, the bulky substrates $\mathbf{5 d}$ and $\mathbf{5 f}$, with the same catalyst loading $(2.5 \%)$, had a far reduced activity in the $4-\mathrm{h}$ time period. When this is increased to $18 \mathrm{~h}$, the improvement is only marginal $(93 \%, 85 \%)$, suggesting the $\mathbf{1 - Y}$ is more subject to steric effects than the previously reported $3 \mathrm{~d} / 4 \mathrm{f}$ catalysts [38]. 

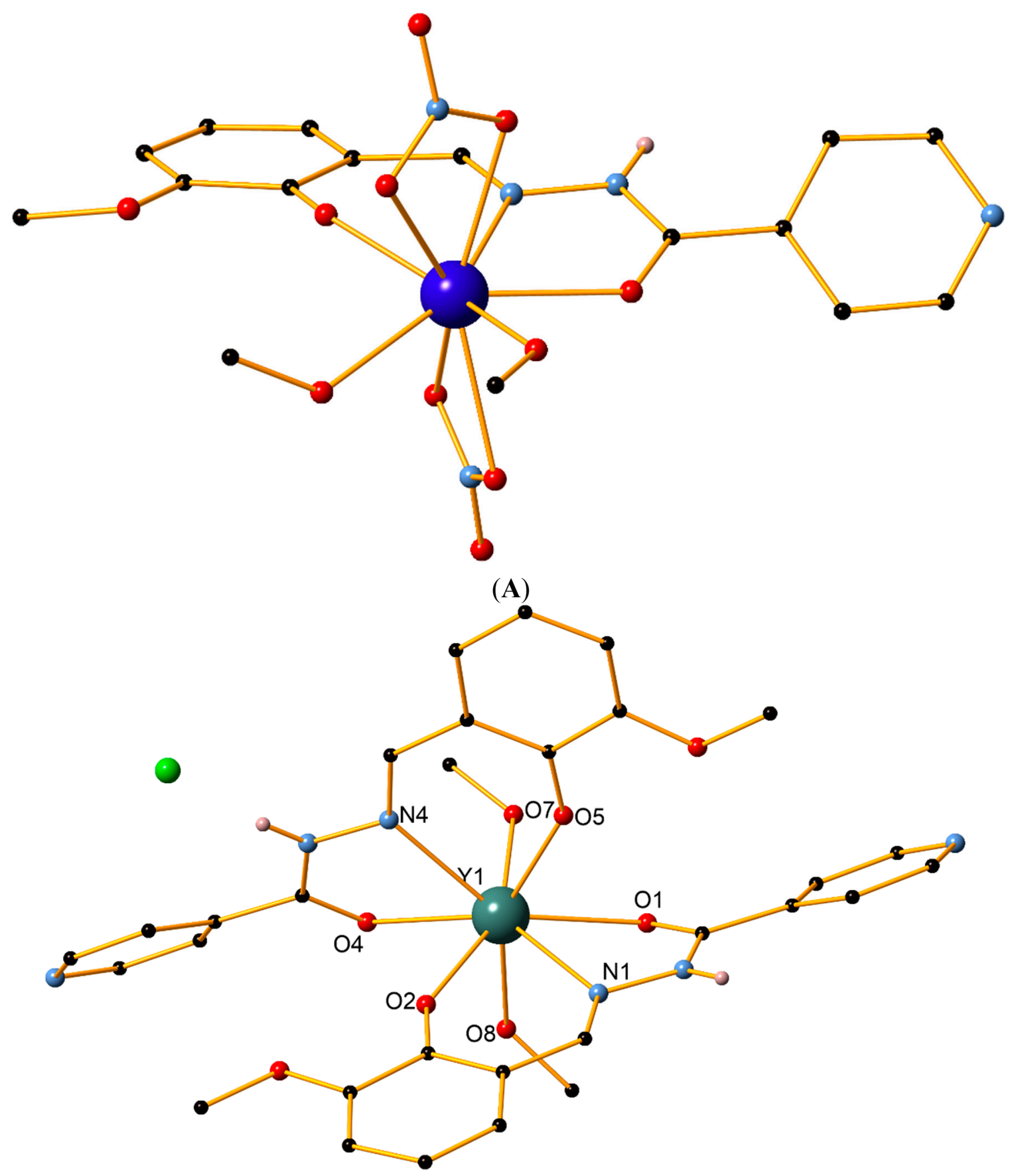

(B)

Figure 3. (A) The structure of the 3-Dy monomer; (B) The structure of compound 4-Y. Certain $\mathrm{H}$ atoms and all lattice solvent molecules are omitted for clarity. Colour code Dy (purple), Y (dark green), Cl (green), C (black), N (light blue), O (red). 
Table 2. Y(III)-catalysed condensation/ring-opening/cyclisation of secondary amines with 2-furaldehyde and condensation/ring opening of primary amines with 2-furaldehyde. Reaction conditions: amine, $1 \mathrm{mmol}$; 2-furaldehyde, $0.5 \mathrm{mmol}$; $4 \mathrm{~A} \mathrm{MS}, 100 \mathrm{mg}$; anhydrous MeCN, $4 \mathrm{~mL}$; room temperature. Yields calculated by isolation of product via column chromatography.

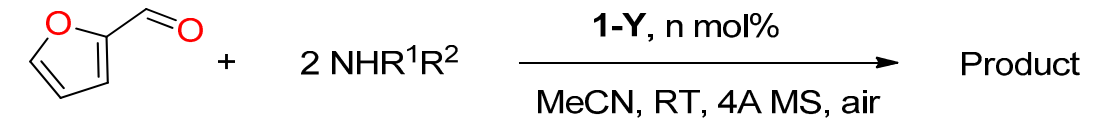

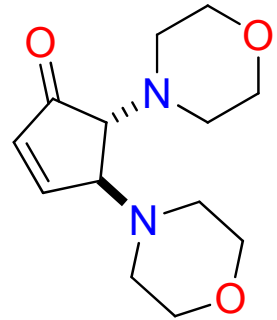

4a $100 \%, 2 \mathrm{~h}$<smiles>O=C1C=C[C@H](N2CCc3ccccc3C2)[C@H]1N1CCc2ccccc2C1</smiles>
$90 \%, 4 \mathrm{~h}$

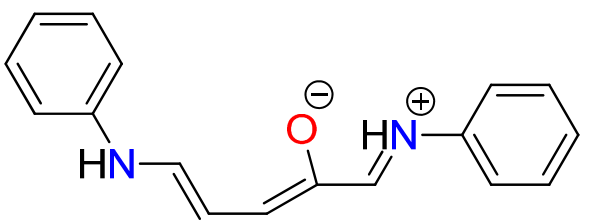

5 a $99 \%, 8 \mathrm{~h}$

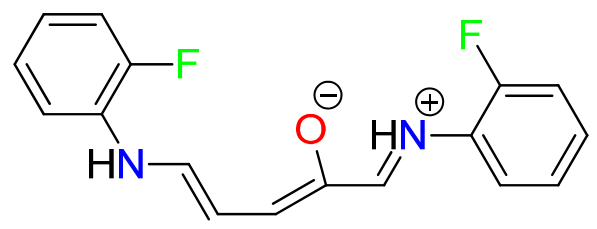

$5 \mathrm{c}$

$75 \%$, 8h<smiles>C=CN(C=C)C1C=CC(=O)C1N(C=C)C=C</smiles>

4b<smiles>O=C1C=CC(N2CCc3ccccc32)[C@H]1N1CCc2ccccc21</smiles>

4c

$91 \%, 4 \mathrm{~h}$ $100 \%, 4 \mathrm{~h}$<smiles>O=C1C=CC(N2CCCc3ccccc32)[C@H]1N1CCCc2ccccc21</smiles>

$$
80 \%, 4 h
$$

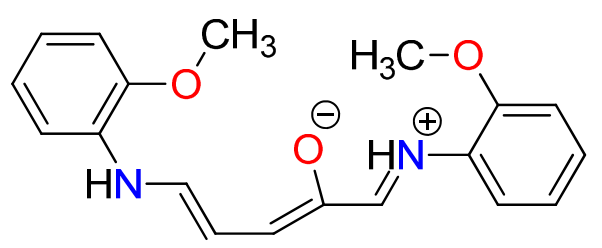

5b

$79 \%$, 8 h

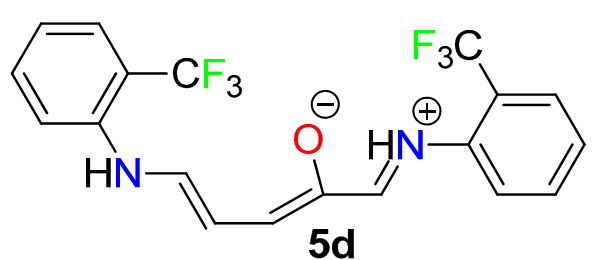

$39 \%$, 8 h

In an effort to understand the catalysis further, we monitored the reaction in situ. 1-Y is only slightly soluble in $\mathrm{MeCN}-d_{3}$, so we opted to run the reaction in DMSO-d6. A solution of $6.9 \mathrm{mg} \mathbf{1 - Y}$ $(\sim 11.5$ mol. $\%)$ in $0.55 \mathrm{~mL}$ DMSO- $d_{6}$ gives a $\mathrm{Y}$ chemical shift of $95.9 \mathrm{ppm}$ changing slightly to $97.4 \mathrm{ppm}$ on the addition of $0.125 \mathrm{mmol}$ morpholine, and all the ${ }^{1} \mathrm{H}$ peaks broadening slightly. After the addition of $0.0625 \mathrm{mmol} 2$-furaldehyde, the reaction at room temperature begins immediately, with $\mathrm{ca}$. $50 \%$ of the furaldehyde forming the corresponding imine from morpholine (most notable, $\mathrm{H}-1$ as a singlet at $5.13 \mathrm{ppm}$, Scheme 2), and only $4 \%$ of the intended product. Whether the imine is a necessary 
intermediate or merely a resting state is not yet clear-this part of the reaction occurs in the absence of a catalyst. There was no difference in the $\mathrm{Y}$ chemical shift with time, and it was not possible to observe any Y catalytic intermediates. After $c a .17 \mathrm{~h}, 5 \%$ furfural remained, $<1 \%$ of the imine adduct, ca. $75 \%$ of the desired product, and $20 \%$ of a second species which slowly increased in concentration, although so far it has not been possible to unambiguously characterise its structure. In addition, $<5 \%$ of morpholine remained (due to overlap with other species it is difficult to be certain to a lower limit of detection), and the ${ }^{1} \mathrm{H}$ peak shape had improved such that the smaller $J$-couplings in furfural are observable, as they are for pure solutions of furfural in DMSO- $d 6$.

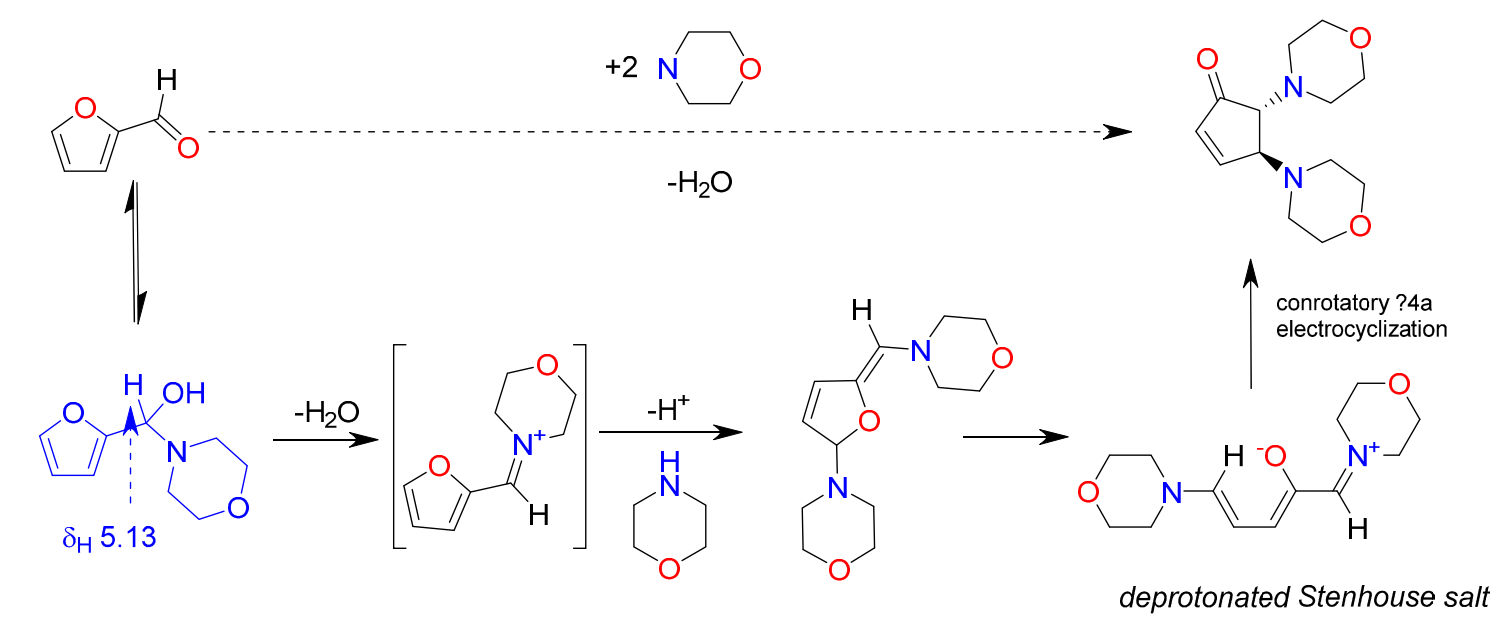

Scheme 2. Modified mechanism for the $\mathrm{Ln}^{\mathrm{III}}$-catalysed synthesis of trans-4,5-Dimorpholin4-yl-cyclopent-2-enone. Possible imine intermediate step shown in blue.

\subsection{Solution Studies}

Electrospray ionization mass spectrometry (ESI-MS) was performed to confirm the identity and behaviour of the compounds in solution. Representative spectra for the compounds are presented in Figures S3-S6. The MS (positive-ion mode) for the Dy (III) complexes 1-Dy and 2-Dy shows one main peak at $497.06 \mathrm{~m} / \mathrm{z}$ which perfectly corresponds to the respective $\left[\mathrm{Dy}(\mathrm{L})(\mathrm{MeOH})_{2}-2 \mathrm{H}\right]^{1+}$ monocationic fragment. The respective isostructural complexes 1-Gd and 2-Gd also behave in a similar fashion, showing one main peak at $491.05 \mathrm{~m} / \mathrm{z}$ that corresponds to the $\left[\mathrm{Gd}(\mathrm{L})(\mathrm{MeOH})_{2}-2 \mathrm{H}\right]^{1+}$ monocationic fragment. Compounds 1-Y and 2-Y exhibit common peaks at 422.04, 629.08 and $986.07 \mathrm{~m} / \mathrm{z}$, corresponding to the $\left[\mathrm{Y}(\mathrm{L})(\mathrm{MeOH})_{2}-\mathrm{H}\right]^{1+},\left[\mathrm{Y}(\mathrm{L})_{2}\right]^{1+}$ and $\left[\mathrm{Y}_{2}(\mathrm{~L})_{3}-2 \mathrm{H}\right]^{1+}$ fragments, respectively. 1-Y shows extra main peaks at $760.96,823.97 \mathrm{~m} / \mathrm{z}$, corresponding to the respective $\left[\mathrm{Y}_{2}(\mathrm{~L})_{2} \mathrm{MeCN}^{1+}\right.$, $\left[\mathrm{Y}_{2}(\mathrm{~L})_{2}(\mathrm{MeCN})(\mathrm{MeOH})_{2}\right]^{1+}$ fragments. For 2-Y two additional peaks appear at 900.18 and $1257.16 \mathrm{~m} / \mathrm{z}$ that match the respective $\left[\mathrm{Y}(\mathrm{L})_{3}+\mathrm{H}\right]^{1+}$ and $\left[\mathrm{Y}_{2}(\mathrm{~L})_{4}-\mathrm{H}\right]^{1+}$ monocationic fragments. These results indicate that compounds behave in a similar way. Uniquely for the Y(III) compounds, the ESI-MS studies suggest that both dimer and monomer forms are present into the solution.

\subsection{Thermal and Powder XRD Studies}

In order to confirm phase purity of the most effective catalysts 1-Dy and 1-Y, these were further characterised through Powder XRD studies, indicating that both compounds are formed in high purity 
(Figure S7). In order to examine the thermal stability of all complexes, TGA was carried out between room temperature and $1000{ }^{\circ} \mathrm{C}$ under $\mathrm{N}_{2}$ atmosphere. The TGA curves are presented in Figure 4 .

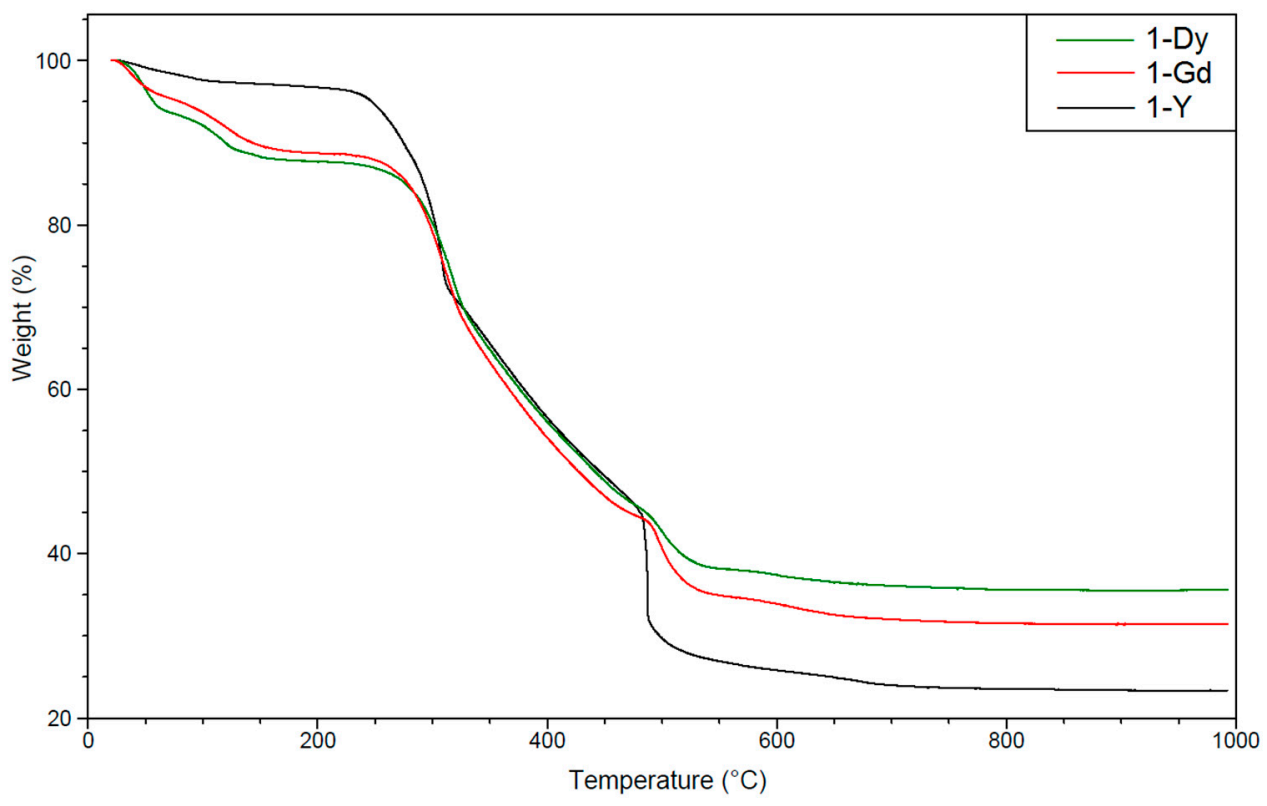

(A)

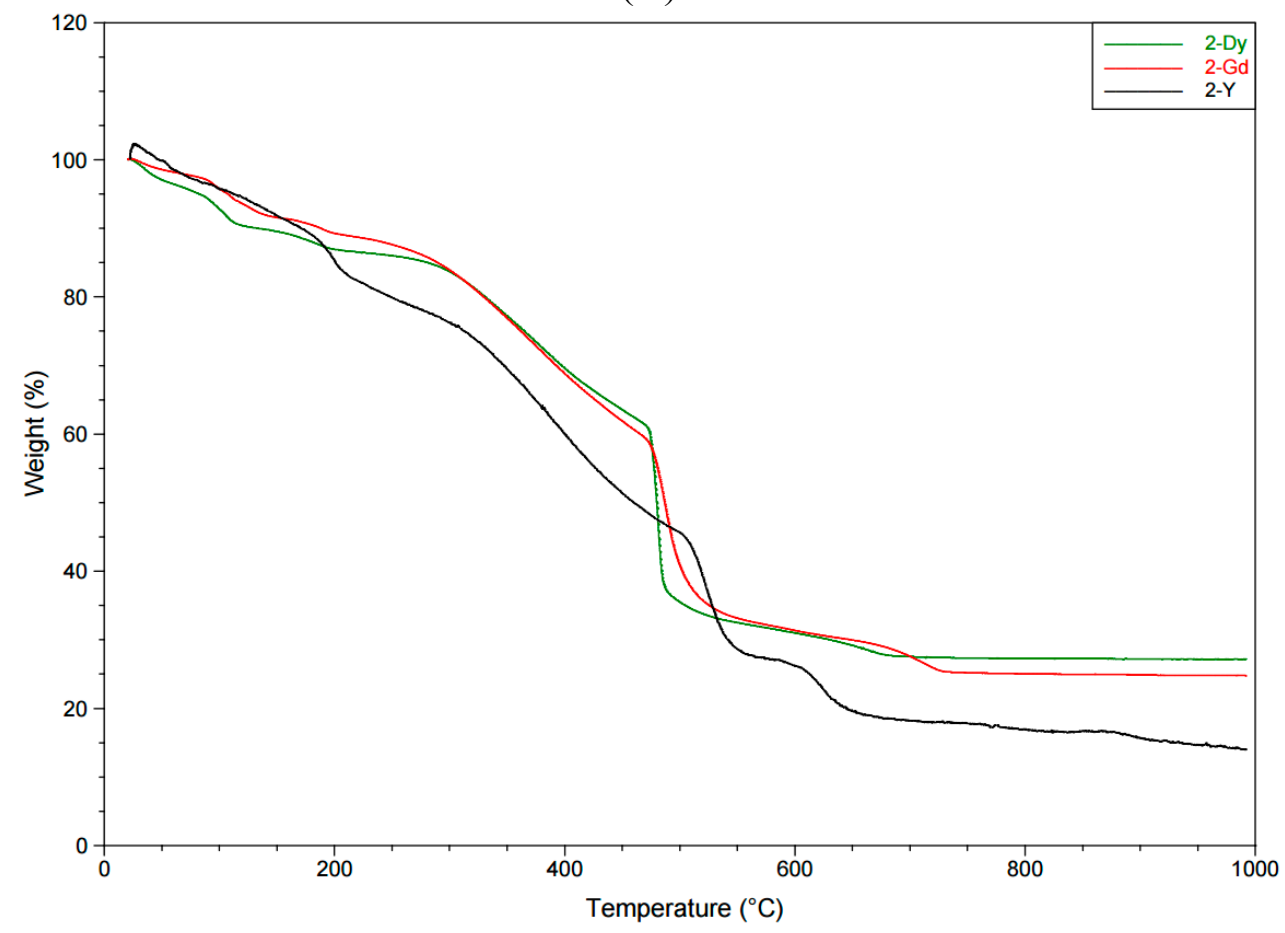

(B)

Figure 4. (A) TGA overlay of 1-Dy, 1-Gd, 1-Y; (B) TGA overlay of 2-Dy, 2-Gd, 2-Y.

Regarding the nitrate-based compounds, the TGA graphs for 1-Dy and 1-Gd are very similar, showing a mass loss at $\sim 150{ }^{\circ} \mathrm{C}$, which corresponds to the loss of respective lattice solvent molecules. The remaining core is stable until the region of $250-300^{\circ} \mathrm{C}$, after which gradual decomposition begins, leaving metal oxide as the final residue. The method was also used to confirm the identity of 1-Gd, which could not be obtained as crystalline material; the first observed mass loss $(10.78 \%)$ at $161{ }^{\circ} \mathrm{C}$ 
corresponds to the loss of two acetonitrile and one methanol molecules (theoretical weight loss: 9.87\%). The second mass loss occurs at $242{ }^{\circ} \mathrm{C}$, corresponding to the gradual decomposition and was measured at $57.88 \%$, within a reasonable range to the expected value of $55.21 \%$.

TGA analysis was further used to confirm the structure of compound 2-Dy and identify the correct number of solvent molecules, which could not be determined through X-ray crystallography due to bad data. The first observed mass loss $(9.96 \%)$ at $132{ }^{\circ} \mathrm{C}$ corresponds to the loss of six water and one methanol molecules (theoretical weight loss: 10.13\%). The second mass loss occurs from 132 to $222{ }^{\circ} \mathrm{C}$ and corresponds to the loss of the lattice chlorine atom (calculated: $3.29 \%$, theoretical: $2.53 \%$ ). Finally, the third loss which begins at $222{ }^{\circ} \mathrm{C}$, attributed to gradual decomposition was measured at $59.61 \%$, in good agreement to the expected value of $60.17 \%$. A similar identification took place for the pseudopolymorph 2-Gd. A continuous mass loss occurs from room temperature up to $196{ }^{\circ} \mathrm{C}$, corresponding in good agreement to the loss of the six water molecules and the lattice chlorine atom (calc.: $10.66 \%$, theor.: $10.71 \%)$. Almost instantly $\left(200^{\circ} \mathrm{C}\right)$ gradual decomposition takes place, with the calculated (64.38\%) and the theoretical (62.24\%) values being in a reasonable range. The bulk material of 2-Y was identified likewise. For $\mathbf{2 - Y}$, the first mass loss is again continuous, occurring from room temperature to $198{ }^{\circ} \mathrm{C}$ and corresponds to the loss of all lattice components (six water molecules, one methanol molecule and one chlorine atom, calc.: $14.49 \%$, theor.: $14.22 \%$ ). The second mass loss begins almost instantly at $200{ }^{\circ} \mathrm{C}$ and corresponds to the gradual decomposition of the remaining core (calc.: $68.45 \%$, theor.: $67.5 \%$ ).

\section{Experimental Section}

\subsection{Materials}

Chemicals (reagent grade) were purchased from Sigma Aldrich (St Louis, MO, USA), Acros Organics (Morris Plains, NJ, USA) and Alfa Aesar (Ward Hill, MA, USA). All experiments were performed under aerobic conditions using materials and solvents as received.

\subsection{Instrumentation}

NMR spectra were measured on a Varian VNMRS solution-state spectrometer (Bruker BioSpin, Rheinstetten, Germany) at $500 \mathrm{MHz}$ at $30^{\circ} \mathrm{C}$ using residual isotopic solvent (DMSO- $d_{5}, \delta_{\mathrm{H}}=2.50 \mathrm{ppm}$ ) as an internal chemical shift reference. ${ }^{1} \mathrm{H}$ DOSY (ledbpgp2s), ${ }^{15} \mathrm{~N}-\mathrm{HMBC}$ and ${ }^{89} \mathrm{Y}$-HMQC spectra were acquired at 298.0 K on a Bruker Avance III 400 instrument (Bruker BioSpin) equipped with a broadband observe probe (BBO). Chemical shifts are quoted in ppm. Coupling constants $(J)$ are recorded in Hz. IR spectra of the samples were recorded over the range of $4000-650 \mathrm{~cm}^{-1}$ on a Perkin Elmer Spectrum One FT-IR spectrometer (PerkinElmer, Waltham, MA, USA) fitted with an UATR polarization accessory (PerkinElmer). ESI-MS was performed on a VG Autospec Fissions instrument (EI at $70 \mathrm{eV}$ ). TGA analysis was performed on a TA Instruments Q-50 model (TA, Surrey, UK) under nitrogen and at a scan rate of $10{ }^{\circ} \mathrm{C} / \mathrm{min}$. X-ray powder diffraction patterns were recorded using a Bruker-AXS D8-Advance diffractometer (Bruker AXS GmbH, Karlsruhe, Germany) equipped with a $\mathrm{Cu}$ sealed-tube radiation source $(\lambda=1.5418 \AA)$ and a secondary beam graphite monochromator. Data were collected from $4^{\circ}$ to $50^{\circ}$ in the $2 \theta$ mode at $5 \mathrm{~s} / \mathrm{step}$. 


\subsection{Crystallography}

Data for 2-Dy, 2-Gd and 1-Y were collected ( $\omega$-scans) at the University of Sussex using an Agilent Xcalibur Eos Gemini Ultra diffractometer (Agilent Technologies, Palo Alto, CA, USA) with CCD plate detector under a flow of nitrogen gas at $173(2) \mathrm{K}$ using Mo K $\alpha$ radiation $(\lambda=0.71073 \AA)$. CRYSALIS CCD and RED software was used respectively for data collection and processing. Reflection intensities were corrected for absorption by the multi-scan method. Data for $\mathbf{4 - Y}$ were collected at the National Crystallography Service, University of Southampton [46] using a Rigaku Saturn 724+ area detector mounted at the window of an FR-E+ rotating anode generator with a Mo anode $(\lambda=0.71075 \AA)$ under a flow of nitrogen gas at 100(2) K. All structures were determined using Olex2 [47], solved using either Superflip [48] or SHELXT [49,50] and refined with SHELXL-2014 [51]. All non-H atoms were refined with anisotropic thermal parameters, and $\mathrm{H}$-atoms were introduced at calculated positions and allowed to ride on their carrier atoms. For 2-Dy and 2-Gd, attempts to model the lattice solvents were unsuccessful despite multiple data collections. Therefore, the solvent mask function of Olex2 [47] was employed to remove the contribution of the electron density associated with those molecules from the intensity data. The presence of those solvent molecules in each structure was confirmed through TGA and/or elemental analysis. Geometric/crystallographic calculations for all structures were performed using PLATON [52], Olex2 [47], and WINGX [49] packages; graphics were prepared with Crystal Maker [53]. CCDC 1430641-1430645.

\subsection{Ligand Synthesis}

The synthesis of $\mathrm{H}_{2} \mathrm{~L} 2$ has been carried out according to the reported synthetic procedure [40], although the authors did not report data for the minor rotamer. Due to peak overlap and low $\mathrm{S} / \mathrm{N}$, only a partial reporting of ${ }^{13} \mathrm{C}$ (via HSQC) and ${ }^{15} \mathrm{~N}$ chemical shifts was possible. Rotamer A. ${ }^{1} \mathrm{H}$ NMR (400 MHz, DMSO-d6) $\delta 12.26$ (br. s, 1H), 10.71 (br. S, 1H), 8.81 (d, $J=4.5 \mathrm{~Hz}, 2 \mathrm{H}), 8.71$ (s, 1H), 7.85 (d, J=4.5 Hz), $7.21(\mathrm{~m}, 1 \mathrm{H}) ., 7.06(\mathrm{~m}, 1 \mathrm{H}), 6.88(\mathrm{~m}, 1 \mathrm{H}), 3.83(\mathrm{~s}, 3 \mathrm{H}) ;{ }^{13} \mathrm{C}$ NMR (100 MHz, DMSO-d $) \delta 161.8,150.8$, 148.5, 147.6, 140.5, 122.0, 119.6, 119.5, 114.4, 56.3; ${ }^{15} \mathrm{~N}$ NMR (40.5 MHz, DMSO-d6) $\delta 326.0,303.2$, 172.0. Rotamer B. ${ }^{1} \mathrm{H}$ NMR (400 MHz, DMSO-d6) $\delta 12.02$ (br. s, 1H), 9.43 (br. S, 1H), 8.71 (m), 8.41 $(\mathrm{s}, 1 \mathrm{H}), 7.64(\mathrm{~m}), 7.00(\mathrm{~m}, 1 \mathrm{H}) ., 6.97(\mathrm{~m}, 1 \mathrm{H}), 6.77(\mathrm{~m}, 1 \mathrm{H}), 3.79(\mathrm{~s}, 3 \mathrm{H}) ;{ }^{13} \mathrm{C}$ NMR (100 MHz, DMSO-d6) $\delta 143.5,123.2,119.7,118.9,56.3 ;{ }^{15} \mathrm{~N}$ NMR $\left(40.5 \mathrm{MHz}, \mathrm{DMSO}-d_{6}\right) \delta 312.1,179.7$.

Synthesis of 1-Dy. The reported synthetic procedure was followed [44].

Synthesis of $\left[\mathrm{Dy}_{2}(\mathrm{HL} 2)_{3} \mathrm{Cl}_{2}\right] \cdot \mathrm{Cl} \cdot\left(\mathrm{H}_{2} \mathrm{O}\right)_{6} \cdot(\mathrm{MeOH})(\mathbf{2}-\mathrm{Dy}) .0 .25 \mathrm{mmol}(0.068 \mathrm{~g})$ of L and $0.37 \mathrm{mmol}$ $(0.099 \mathrm{~g})$ of $\mathrm{DyCl}_{3}$ were dissolved in $\mathrm{MeCN} / \mathrm{MeOH}(15: 5 \mathrm{~mL})$ while stirring to produce an orange solution, which was further treated with $1 \mathrm{mmol}$ pyridine $(81.0 \mu \mathrm{L})$. The resulting yellow solution was stirred for a further $15 \mathrm{~min}$, filtrated, then left to evaporate slowly. Orange block crystals were obtained after 15 days. Yield: 46\%. Selected IR peaks $\left(\mathrm{cm}^{-1}\right)$ : 3115 (w), 1600 (s), 1566 (m), 1521 (w), 1454 (s), 1382 (m), 1318 (w), 1279 (m), 1222 (s), 1170 (w), 1108 (w), 1066 (m), 1007 (w), 960 (m), 908 (w), 851 (m), 785 (w), 741 (s), 694 (s). Elemental analysis for $\mathrm{C}_{43} \mathrm{H}_{52} \mathrm{Cl}_{3} \mathrm{Dy}_{2} \mathrm{~N}_{9} \mathrm{O}_{16}$ : C 37.36, H 3.79, N 9.12; found $\mathrm{C} 35.49, \mathrm{H} \mathrm{3.60,} \mathrm{N}$ 8.75. This result corresponds to the loss of one methanol molecule and the presence of ten water molecules: $\mathrm{C}_{42} \mathrm{H}_{56} \mathrm{Cl}_{3} \mathrm{Dy}_{2} \mathrm{~N}_{9} \mathrm{O}_{19}$ : C 35.47, H 3.97, N 8.86. 
Synthesis of [Dy(HL2)(NO3 $\left.)_{2}(\mathrm{MeOH})_{2}\right](3-\mathrm{Dy})$. A solution of $0.3 \mathrm{mmol}(0.133 \mathrm{~g})$ of $\mathrm{Dy}\left(\mathrm{NO}_{3}\right)_{3} \cdot 5 \mathrm{H}_{2} \mathrm{O}$ in $12.5 \mathrm{~mL} \mathrm{MeOH}$ was added to a solution of $0.15 \mathrm{mmol}(0.041 \mathrm{~g})$ of $\mathrm{L}$ in $12.5 \mathrm{~mL} \mathrm{MeOH}$ while stirring. The resulting orange solution was stirred for a further $15 \mathrm{~min}$, filtrated, then kept in a stored vial. Yellow/orange block crystals were obtained after 5 days. Yield: $21 \%$. Selected IR peaks $\left(\mathrm{cm}^{-1}\right): 3087(\mathrm{w})$, 1607 (s), 1549 (m), 1458 (s), 1430 (m), 1412 (m), 1394 (m), 1301 (w), 1245 (m), 1221 (s), 1169 (w), 1082 (w), 1063 (m), 1025 (w), 1008 (w), 967 (m), 912 (w), 867 (w), 850 (m), 740 (s), 699 (s), 639 (m).

Synthesis of $\left[\mathrm{Gd}_{2}\left(\mathrm{~L}_{2}\right)_{2}\left(\mathrm{NO}_{3}\right)_{2}(\mathrm{MeOH})_{2}\right] \cdot \mathrm{MeCN} \cdot \mathrm{MeOH}(\mathbf{1 - G d})$. The reported synthetic procedure was followed [44], with $\mathrm{Gd}\left(\mathrm{NO}_{3}\right)_{3} \cdot 6 \mathrm{H}_{2} \mathrm{O}$ as the metal salt. A yellow powder was obtained and its identity was confirmed through IR and TGA. Selected IR peaks $\left(\mathrm{cm}^{-1}\right)$ : $3135(\mathrm{w}), 1605(\mathrm{~s}), 1572(\mathrm{~m}), 1521(\mathrm{w})$, 1456 (s), 1408 (w), 1380 (m), 1306 (w), 1266 (m), 1241 (w), 1219 (s), 1174 (w), 1105 (w), 1078 (m), $1058(\mathrm{w}), 1009(\mathrm{w}), 960(\mathrm{~m}), 913(\mathrm{w}), 849(\mathrm{~m}), 786(\mathrm{w}), 740(\mathrm{~s}), 692(\mathrm{~s})$.

Synthesis of $\left[\mathrm{Gd}_{2}(\mathrm{HL} 2)_{3} \mathrm{Cl}_{2}\right] \cdot \mathrm{Cl} \cdot\left(\mathrm{H}_{2} \mathrm{O}\right)_{6}(\mathbf{2}-\mathbf{G d})$. A synthetic procedure similar to 2-Dy was followed, with $0.29 \mathrm{mmol}(0.107 \mathrm{~g})$ of $\mathrm{GdCl}_{3} \cdot 6 \mathrm{H}_{2} \mathrm{O}$ added. Orange block crystals were obtained after 7 days. Yield: 28\%. Selected IR peaks (cm $\left.{ }^{-1}\right): 3133$ (w), 2944 (w), 2834 (w), 1600 (s), 1547 (m), 1454 (s), 1408 (w), 1380 (m), 1317 (w), 1288 (m), 1221 (s), 1172 (w), 1105 (w), $1078(\mathrm{w}), 1063$ (m), $1024(\mathrm{w})$, $965(\mathrm{~m}), 904(\mathrm{w}), 851(\mathrm{~m}), 786(\mathrm{w}), 740(\mathrm{~s}), 692(\mathrm{~s})$.

Synthesis of $\left[\mathrm{Y}_{2}(\mathrm{~L} 2)_{2}\left(\mathrm{NO}_{3}\right)_{2}(\mathrm{EtOH})_{0.32}\left(\mathrm{H}_{2} \mathrm{O}\right)_{0.68}\right] \cdot 0.68 \mathrm{EtOH}(\mathbf{1 - Y})$ The reported synthetic procedure was followed [44], with $\mathrm{Y}\left(\mathrm{NO}_{3}\right)_{3} \cdot 6 \mathrm{H}_{2} \mathrm{O}$ as the metal salt. A yellow powder was obtained, which was then recrystallised in EtOH/hexane to produce yellow block crystals after 1 day. Yield: 18\%. Selected IR peaks (cm $\left.{ }^{-1}\right): 3148(\mathrm{w}), 2953(\mathrm{w}), 1606$ (s), $1574(\mathrm{~m}), 1521$ (s), 1459 (s), 1370 (m), 1320 (m), 1268 (m), 1244 (m), 1220 (s), 1172 (w), 1098 (w), 1080 (m), 1014 (w), 962 (m), 920 (w), 849 (m), 785 (w), 739 (s), 707 (s). A minor impurity was insoluble in DMSO0-d6, so NMR samples were filtered through a $0.45 \mu \mathrm{m}$ syringe filter. The ${ }^{15} \mathrm{~N}-\mathrm{HMBC} \mathrm{S} / \mathrm{N}$ was too low to identify the second $\mathrm{N}$ atom in the hydrazide bridge. ${ }^{1} \mathrm{H}$ NMR (400 MHz, DMSO- $\left.d_{6}\right) \delta 8.63(\mathrm{~m}, 2 \mathrm{H}), 8.43$ (br. s, $1 \mathrm{H}$ ), $7.90(\mathrm{~m}, 2 \mathrm{H}), 6.88(\mathrm{dd}, J=7.9,1.4 \mathrm{~Hz}, 1 \mathrm{H}), 6.83(\mathrm{dd}, J=7.7,1.4 \mathrm{~Hz}, 1 \mathrm{H}), 6.43(\mathrm{t}, J=7.7 \mathrm{~Hz}, 1 \mathrm{H}), 3.73$ $(\mathrm{s}, 3 \mathrm{H}) ;{ }^{13} \mathrm{C}$ NMR (100 MHz, DMSO-d6) $\delta 166.9,157.8$ (br.), 157.0 (d, $\left.J_{\mathrm{CY}}=2.2 \mathrm{~Hz}\right), 151.1,150.2$, 143.9 (br.), 126.1, 122.1, 121.3, 114.7. 113.4, 55.8; ${ }^{15} \mathrm{~N}$ NMR (40.5 MHz, DMSO- $d_{6}$ ) $\delta$ 319.7, 314.4; ${ }^{89} \mathrm{Y}$ NMR (19.6 MHz, DMSO-d6) $\delta$ 92.4. D $2.0 \times 10^{-10} \mathrm{~m}^{2} \cdot \mathrm{s}^{-1}$.

Synthesis of $\left[\mathrm{Y}_{2}(\mathrm{HL} 2)_{3} \mathrm{Cl}_{2}\right] \cdot \mathrm{Cl} \cdot\left(\mathrm{H}_{2} \mathrm{O}\right)_{6} \cdot(\mathrm{MeOH})$ (2-Y). The synthetic procedure for 2-Dy was followed, with $\mathrm{YCl}_{3} \cdot 6 \mathrm{H}_{2} \mathrm{O}$ as the metal salt. A yellow powder was obtained and its identity was confirmed through IR and TGA. Selected IR peaks $\left(\mathrm{cm}^{-1}\right)$ : 3145 (w), 2938 (w), 2847 (w), 1599 (s), 1549 (m), 1517 (w), 1451 (s), $1411(\mathrm{w}), 1379$ (m), 1288 (m), 1220 (s), 1168 (w), 1063 (m), 1005 (w), 966 (m), 905 (w), 847 (m), 787 (w), 739 (s), 692 (s). ${ }^{1} \mathrm{H}$ NMR (400 MHz, DMSO-d6) $\delta 8.61(\mathrm{~m}, 2 \mathrm{H}), 8.41$ (br. s, 1H), $7.89(\mathrm{~m}, 2 \mathrm{H}), 6.85(\mathrm{~m}, 1 \mathrm{H}) ., 6.83(\mathrm{~m}, 1 \mathrm{H}), 6.43(\mathrm{~m}, 1 \mathrm{H}), 3.73(\mathrm{~s}, 3 \mathrm{H}) ;{ }^{13} \mathrm{C}$ NMR $(100 \mathrm{MHz}$, DMSO-d $d_{6} \delta 167.1\left(\mathrm{~d}, J_{\mathrm{CY}}=1.3 \mathrm{~Hz}\right), 158.0,156.7\left(\mathrm{~d}, J_{\mathrm{CY}}=2.0 \mathrm{~Hz}\right), 151.0,150.1,144.3,126.1,122.1$, 121.5, 114.5. 113.3, 55.8; ${ }^{15} \mathrm{~N}$ NMR (40.5 MHz, DMSO- $\left.d_{6}\right) \delta 323.7,321.7\left({ }^{1} J_{\mathrm{YN}}=9.1 \mathrm{~Hz} *\right), 284.9$; ${ }^{89} \mathrm{Y}$ NMR (19.6 MHz, DMSO-d6) $\delta$ 111.0. D $2.2 \times 10^{-10} \mathrm{~m}^{2} \cdot \mathrm{s}^{-1}$. *Measured via high-resolution aliased ${ }^{15} \mathrm{~N}-\mathrm{HMBC}$ spectra.

Synthesis of $\left[\mathrm{Y}(\mathrm{HL} 2)_{2}(\mathrm{MeOH})_{2}\right] \cdot \mathrm{Cl} \cdot \mathrm{MeCN}($ 4-Y). A synthetic procedure similar to 2-Dy was followed, with $0.125 \mathrm{mmol}(0.038 \mathrm{~g})$ of $\mathrm{YCl}_{3} \cdot 6 \mathrm{H}_{2} \mathrm{O}$ added. Small yellow block crystals were obtained 
after 1 day. Yield: 29\%. Selected IR peaks $\left(\mathrm{cm}^{-1}\right)$ : 3140 (w), 2935 (w), $2822(\mathrm{w}), 1596$ (s), $1544(\mathrm{~m})$, 1444 (s), 1415 (w), 1389 (m), 1320 (w), 1218 (s), 1165 (w), 1108 (w), 1065 (m), 1007 (w), 975 (m), $907(\mathrm{w}), 855(\mathrm{~m}), 788(\mathrm{w}), 739(\mathrm{~s}), 692(\mathrm{~s})$.

2-Furaldehyde morpholine hemi-aminal. ${ }^{1} \mathrm{H}$ NMR (400 MHz, DMSO- $\left.d 6\right) \delta 7.58(\mathrm{dd}, J=1.9,0.9 \mathrm{~Hz}$, 1H), $6.40(\mathrm{dd}, 3.2,1.8 \mathrm{~Hz}, 1 \mathrm{H}), 6.32(\mathrm{dt}, 3.2,0.9 \mathrm{~Hz}, 1 \mathrm{H}), 5.13(\mathrm{~s}, 1 \mathrm{H}), 3.55(\mathrm{~m}, 4 \mathrm{H}), 2.51$ (m, 4.8H*). *Overlaps with DMSO- $d 5 ;{ }^{13} \mathrm{C}$ NMR (100 MHz, DMSO-d6).

\section{Conclusions}

To summarise, a series of $4 \mathrm{f}$ compounds has been obtained and tested for their catalytic activity towards trans-4,5-diaminocyclopent-2-enones from 2-furaldehyde and primary or secondary amines. From this systematic study we have derived that the afforded Y(III) compounds exhibit remarkable activity as homogeneous catalysts and at a lower cost compared to other lanthanides. The monitored performance of those compounds through ${ }^{1} \mathrm{H}$ and ${ }^{89} \mathrm{Y}$ NMR studies has also allowed us to further understand the catalytic reaction; as a result, we have proposed an extra step in its reported mechanism (Scheme 2). However, the presence of two different ligand rotamers in solution, as well as both dimer and monomer forms for the Y(III) compounds make this system a less than ideal candidate for further investment in this field. Despite that, this work certainly demonstrates that the plethora of polynuclear $4 \mathrm{f}$ compounds reported to date could exhibit other interesting properties, apart from molecular magnetism.

\section{Supplementary Materials}

Supplementary materials can be found at http://www.mdpi.com/2304-6740/3/4/0448/s1 .

\section{Acknowledgments}

We thank the EPSRC (UK) for funding (grant number EP/M023834/1) and the EPSRC UK National Crystallography Service at the University of Southampton for the collection of the crystallographic data for compound 4-Y.

\section{Author Contributions}

Edward Loukopoulos and George E. Kostakis conceived and designed the experiments; Edward Loukopoulos and Kieran Griffiths performed the experiments; Edward Loukopoulos, Geoffrey R. Akien and George E. Kostakis analysed the data; Alaa Abdul-Sada and Nikolaos Kourkoumelis contributed reagents/materials/analysis tools; Edward Loukopoulos, Geoffrey R. Akien and George E. Kostakis wrote the paper.

\section{Conflicts of Interest}

The authors declare no conflict of interest. 


\section{References}

1. Zheng, Z. Ligand-controlled self-assembly of polynuclear lanthanide-oxo/hydroxo complexes: From synthetic serendipity to rational supramolecular design. Chem. Commun. 2001, 2521-2529, doi:10.1039/B107971A.

2. D’Alessio, D.; Sobolev, A.N.; Skelton, B.W.; Fuller, R.O.; Woodward, R.C.; Lengkeek, N.A.; Fraser, B.H.; Massi, M.; Ogden, M.I. Lanthanoid "bottlebrush" clusters: Remarkably elongated metal-oxo core structures with controllable lengths. J. Am. Chem. Soc. 2014, 136, 15122-15125.

3. Thielemann, D.T.; Wagner, A.T.; Lan, Y.; Oña-Burgos, P.; Fernández, I.; Rösch, E.S.; Kölmel, D.K.; Powell, A.K.; Bräse, S.; Roesky, P.W. Peptoid-ligated pentadecanuclear yttrium and dysprosium hydroxy clusters. Chem. Eur. J. 2015, 21, 2813-2820.

4. Wu, M.; Jiang, F.; Kong, X.; Yuan, D.; Long, L.; Al-Thabaiti, S.A.; Hong, M. Two polymeric 36-metal pure lanthanide nanosize clusters. Chem. Sci. 2013, 4, 3104-3109.

5. Peng, J.-B.; Kong, X.-J.; Zhang, Q.-C.; Orendáč, M.; Prokleška, J.; Ren, Y.-P.; Long, L.-S.; Zheng, Z.; Zheng, L.-S. Beauty, symmetry, and magnetocaloric effect-Four-shell keplerates with 104 lanthanide atoms. J. Am. Chem. Soc. 2014, 136, 17938-17941.

6. Woodruff, D.N.; Winpenny, R.E.P.; Layfield, R.A. Lanthanide single-molecule magnets. Chem. Rev. 2013, 113, 5110-5148.

7. Zhang, P.; Guo, Y.-N.; Tang, J. Recent advances in dysprosium-based single molecule magnets: Structural overview and synthetic strategies. Coord. Chem. Rev. 2013, 257, 1728-1763.

8. Amoroso, A.J.; Pope, S.J.A. Using lanthanide ions in molecular bioimaging. Chem. Soc. Rev. 2015, 44, 4723-4442.

9. Bünzli, J.-C. G. On the design of highly luminescent lanthanide complexes. Coord. Chem. Rev. 2015, 293-294, 19-47.

10. Eliseeva, S.V.; Bünzli, J.-C.G. Lanthanide luminescence for functional materials and bio-sciences. Chem. Soc. Rev. 2010, 39, 189-227.

11. Anastasiadis, N.C.; Granadeiro, C.M.; Klouras, N.; Cunha-Silva, L.; Raptopoulou, C.P.; Psycharis, V.; Bekiari, V.; Balula, S.S.; Escuer, A.; Perlepes, S.P. Dinuclear lanthanide(III) complexes by metal-ion-assisted hydration of di-2-pyridyl ketone azine. Inorg. Chem. 2013, 52, 4145-4147.

12. Robinson, J.R.; Gu, J.; Carroll, P.J.; Schelter, E.J.; Walsh, P.J. Exchange processes in Shibasaki's rare earth alkali metal BINOLate frameworks and their relevance in multifunctional asymmetric catalysis. J. Am. Chem. Soc. 2015, 137, 7135-7144.

13. Roesky, P.W.; Canseco-Melchor, G.; Zulys, A. A pentanuclear yttrium hydroxo cluster as an oxidation catalyst. Catalytic oxidation of aldehydes in the presence of air. Chem. Commun. 2004, 738-739.

14. Bi, Y.; Wang, X.-T.; Liao, W.; Wang, X.; Deng, R.; Zhang, H.; Gao, S. Thiacalix[4]arene-supported planar $\operatorname{Ln}(4)\left(\mathrm{Ln}=\mathrm{Tb}^{\mathrm{III}}\right.$, Dy $\left.{ }^{\mathrm{III}}\right)$ clusters: Toward luminescent and magnetic bifunctional materials. Inorg. Chem. 2009, 48, 11743-11747.

15. Alexandropoulos, D.I.; Fournet, A.; Cunha-Silva, L.; Mowson, A.M.; Bekiari, V.; Christou, G.; Stamatatos, T.C. Fluorescent naphthalene diols as bridging ligands in $\mathrm{Ln}^{\mathrm{III}}$ cluster chemistry: Synthetic, structural, magnetic, and photophysical characterization of $\mathrm{Ln}^{\mathrm{III}} 8$ "Christmas Stars." Inorg. Chem. 2014, 53, 5420-5422. 
16. Pointillart, F.; le Guennic, B.; Golhen, S.; Cador, O.; Maury, O.; Ouahab, L. A redox-active luminescent ytterbium based single molecule magnet. Chem. Commun. 2013, 49, 615-617.

17. Mazarakioti, E.C.; Poole, K.M.; Cunha-Silva, L.; Christou, G.; Stamatatos, T.C. A new family of $\mathrm{Ln}_{7}$ clusters with an ideal $D_{3 \mathrm{~h}}$ metal-centered trigonal prismatic geometry, and SMM and photoluminescence behaviors. Dalton Trans. 2014, 43, 11456-11460.

18. Bag, P.; Rastogi, C.K.; Biswas, S.; Sivakumar, S.; Mereacre, V.; Chandrasekhar, V. Homodinuclear lanthanide $\left\{\mathrm{Ln}_{2}\right\}(\mathrm{Ln}=\mathrm{Gd}, \mathrm{Tb}, \mathrm{Dy}, \mathrm{Eu})$ complexes prepared from an $o$-vanillin based ligand: Luminescence and single-molecule magnetism behavior. Dalton Trans. 2015, 44, 4328-4340.

19. Chandrasekhar, V.; Bag, P.; Colacio, E. Octanuclear $\left\{\operatorname{Ln}^{\mathrm{III}} 8\right\}(\mathrm{Ln}=\mathrm{Gd}, \mathrm{Tb}, \mathrm{Dy}, \mathrm{Ho})$ macrocyclic complexes in a cyclooctadiene-like conformation: Manifestation of slow relaxation of magnetization in the Dy ${ }^{\mathrm{III}}$ derivative. Inorg. Chem. 2013, 52, 4562-4570.

20. Pasatoiu, T.D.; Tiseanu, C.; Madalan, A.M.; Jurca, B.; Duhayon, C.; Sutter, J.P.; Andruh, M. Study of the luminescent and magnetic properties of a series of heterodinuclear $\left[\mathrm{Zn}^{\mathrm{II}} \mathrm{Ln}^{\mathrm{III}}\right]$ complexes. Inorg. Chem. 2011, 50, 5879-5889.

21. Ehama, K.; Ohmichi, Y.; Sakamoto, S.; Fujinami, T.; Matsumoto, N.; Mochida, N.; Ishida, T.; Sunatsuki, Y.; Tsuchimoto, M.; Re, N. Synthesis, structure, luminescent, and magnetic properties of carbonato-bridged $\mathrm{Zn}_{2}{ }_{2} \mathrm{Ln}^{\mathrm{III}}{ }_{2}$ complexes $\left[\left(\mu_{4}-\mathrm{CO}_{3}\right)_{2}\left\{\mathrm{Zn}^{\mathrm{II}} \mathrm{L}^{n} \mathrm{Ln}^{\mathrm{III}}\left(\mathrm{NO}_{3}\right)\right\}_{2}\right]\left(\mathrm{Ln}^{\mathrm{III}}=\mathrm{Gd}^{\mathrm{III}}, \mathrm{Tb}^{\mathrm{III}}\right.$, Dy ${ }^{\text {III; }} \mathrm{L}^{1}=N, N^{\prime}$-bis(3-methoxy-2-oxybenzylidene)-1,3-propanediaminato, $\mathrm{L}^{2}=N, N^{\prime}$-bis(3-ethoxy2-oxybenzylidene)-1,3-propanediaminato). Inorg. Chem. 2013, 52, 12828-12841.

22. Goura, J.; Mereacre, V.; Novitchi, G.; Powell, A.K.; Chandrasekhar, V. Homometallic Fe ${ }^{\mathrm{III}} 4$ and heterometallic $\left\{\mathrm{Fe}^{\mathrm{III}}{ }_{4} \mathrm{Ln}^{\mathrm{III}} 2\right\} \quad(\mathrm{Ln}=\mathrm{Dy}, \mathrm{Tb})$ complexes-Syntheses, structures, and magnetic properties. Eur. J. Inorg. Chem. 2015, 2015, 156-165.

23. Ke, H.; Zhao, L.; Guo, Y.; Tang, J. A Dy6 cluster displays slow magnetic relaxation with an edge-to-edge arrangement of two Dy3 triangles. Eur. J. Inorg. Chem. 2011, 2011, 4153-4156.

24. Liao, S.; Yang, X.; Jones, R. A. Self-assembly of luminescent hexanuclear lanthanide salen complexes. Cryst. Growth Des. 2012, 12, 970-974.

25. Sarwar, M.; Madalan, A.M.; Tiseanu, C.; Novitchi, G.; Maxim, C.; Marinescu, G.; Luneau, D.; Andruh, M. A new synthetic route towards binuclear 3d-4f complexes, using non-compartmental ligands derived from $o$-vanillin. Syntheses, crystal structures, magnetic and luminescent properties. New J. Chem. 2013, 37, 2280-2292.

26. Mondal, K.C.; Kostakis, G.E.; Lan, Y.; Powell, A.K. Magnetic properties of five planar defect dicubanes of $\left[\mathrm{Ln}^{\mathrm{III}} 4\left(\mu_{3}-\mathrm{OH}\right)_{2}(\mathrm{~L})_{4}(\mathrm{HL})_{2}\right] \cdot 2 \mathrm{THF}(\mathrm{Ln}=\mathrm{Gd}, \mathrm{Tb}, \mathrm{Dy}, \mathrm{Ho}$ and Er). Polyhedron 2013, 66, $268-273$.

27. Gómez, V.; Vendier, L.; Corbella, M.; Costes, J.-P. Tetranuclear [Co-Gd]2 complexes: Aiming at a better understanding of the 3d-Gd magnetic interaction. Inorg. Chem. 2012, 51, 6396-6404.

28. Athanasopoulou, A.A.; Pilkington, M.; Raptopoulou, C.P.; Escuer, A.; Stamatatos, T.C. Structural aesthetics in molecular nanoscience: A unique Ni26 cluster with a "rabbit-face" topology and a discrete Ni18 "molecular chain". Chem. Commun. 2014, 50, 14942-14945.

29. Tziotzi, T.G.; Tzimopoulos, D.I.; Lis, T.; Inglis, R.; Milios, C.J. Dodecanuclear [MnLn] species: Synthesis, structures and characterization of magnetic relaxation phenomena. Dalton Trans. 2015, 44, 11696-11699. 
30. Meng, Z.-S.; Guo, F.-S.; Liu, J.-L.; Leng, J.-D.; Tong, M.-L. Heterometallic cubane-like $\left\{\mathrm{M}_{2} \mathrm{Ln}_{2}\right\}$ $(\mathrm{M}=\mathrm{Ni}, \mathrm{Zn} ; \mathrm{Ln}=, \mathrm{Gd}, \mathrm{Dy})$ and $\left\{\mathrm{Ni}_{2} \mathrm{Y}_{2}\right\}$ aggregates. Synthesis, structures and magnetic properties. Dalton Trans. 2012, 41, 2320-2329.

31. Fan, L.-L.; Guo, F.-S.; Yun, L.; Lin, Z.-J.; Herchel, R.; Leng, J.-D.; Ou, Y.-C.; Tong, M.-L. Chiral transition metal clusters from two enantiomeric schiff base ligands. Synthesis, structures, CD spectra and magnetic properties. Dalton Trans. 2010, 39, 1771-1780.

32. Thio, Y.; Toh, S.W.; Xue, F.; Vittal, J.J. Self-assembly of a 15-nickel metallamacrocyclic complex derived from the L-glutamic acid Schiff base ligand. Dalton Trans. 2014, 43, 5998-6001.

33. Berkoff, B.; Griffiths, K.; Abdul-Sada, A.; Tizzard, G.J.; Coles, S.; Escuer, A.; Kostakis, G.E. A new family of high nuclearity CoII/DyIII coordination clusters possessing robust and unseen topologies. Dalton Trans. 2015, 44, 12788-12795.

34. Nemec, I.; Machata, M.; Herchel, R.; Boča, R.; Trávníček, Z. A new family of $\mathrm{Fe}_{2} \mathrm{Ln}$ complexes built from mononuclear anionic Schiff base subunits. Dalton Trans. 2012, 41, 14603-14610.

35. Costes, J.-P.; Duhayon, C. An ionic dysprosium complex made of a hexanuclear Dy6 cationic cluster and a mononuclear Dy anionic unit. Eur. J. Inorg. Chem. 2014, 2014, 4745-4749.

36. Loukopoulos, E.; Berkoff, B.; Abdul-Sada, A.; Tizzard, G. J.; Coles, S. J.; Escuer, A.; Kostakis, G.E. A disk-like $\mathrm{Co}_{3}{ }_{3} \mathrm{Dy}^{\mathrm{III}}{ }_{4}$ coordination cluster exhibiting single molecule magnet behavior. Eur. J. Inorg. Chem. 2015, 2015, 2646-2649.

37. Andruh, M. The exceptionally rich coordination chemistry generated by Schiff-base ligands derived from $o$-vanillin. Dalton Trans. 2015, 44, 16633-16653.

38. Griffiths, K.; Gallop, C.W.D.; Abdul-Sada, A.; Vargas, A.; Navarro, O.; Kostakis, G.E. Heteronuclear $3 \mathrm{~d} / \mathrm{Dy}^{\mathrm{III}}$ coordination clusters as catalysts in a domino reaction. Chem. Eur. J. 2015, $21,6358-6361$.

39. Li, S.-W.; Batey, R.A. Mild lanthanide(III) catalyzed formation of 4,5-diaminocyclopent-2-enones from 2-furaldehyde and secondary amines: A domino condensation/ring-opening/electrocyclization process. Chem. Commun. 2007, 3759-3761.

40. Lin, P.-H.; Gorelsky, S.; Savard, D.; Burchell, T.J.; Wernsdorfer, W.; Clérac, R.; Murugesu, M. Synthesis, characterisation and computational studies on a novel one-dimensional arrangement of Schiff-base $\mathrm{Mn}_{3}$ single-molecule magnet. Dalton Trans. 2010, 39, 7650-7658.

41. Monfared, H. H.; Chamayou, A.-C.; Khajeh, S.; Janiak, C. Can a small amount of crystal solvent be overlooked or have no structural effect? Isomorphous non-stoichiometric hydrates (pseudo-polymorphs): The case of salicylaldehyde thiosemicarbazone. CrystEngComm 2010, 12, 3526-3530.

42. Nangia, A. Pseudopolymorph: Retain this widely accepted term. Cryst. Growth Des. 2006, 6, $2-4$.

43. Dokorou, V.N.; Powell, A.K.; Kostakis, G.E. Two pseudopolymorphs derived from alkaline earth metals and the pseudopeptidic ligand trimesoyl-tris-glycine. Polyhedron 2013, 52, 538-544.

44. Lin, P.-H.; Burchell, T.J.; Clerac, R.; Murugesu, M. Dinuclear dysprosium(III) single-molecule magnets with a large anisotropic barrier. Angew. Chem. Int. Ed. 2008, 47, 8848-8851.

45. Llunell, M.D.; Casanova, J.; Cirera, P.; Alemany, S.A. SHAPE Version 2.0; SHAPE: Barcelona, Spain, 2010.

46. Coles, S.J.; Gale, P.A. Changing and challenging times for service crystallography. Chem. Sci. 2012, 3, 683-689. 
47. Dolomanov, O.V.; Blake, A.J.; Champness, N.R.; Schröder, M. OLEX: New software for visualization and analysis of extended crystal structures. J. Appl. Crystallogr. 2003, 36, 1283-1284.

48. Palatinus, L.; Chapuis, G. SUPERFLIP-A computer program for the solution of crystal structures by charge flipping in arbitrary dimensions. J. Appl. Crystallogr. 2007, 40, 786-790.

49. Farrugia, L.J. Win $G X$ suite for small-molecule single-crystal crystallography. J. Appl. Crystallogr. 1999, 32, 837-838.

50. Sheldrick, G.M. SHELXT-Integrated space-group and crystal-structure determination. Acta Crystallogr. Sect. A 2015, 71, 3-8.

51. Sheldrick, G.M. A short history of SHELX. Acta Crystallogr. Sect. A 2008, 64, 112-122.

52. Spek, A.L. Single-crystal structure validation with the program PLATON. J. Appl. Crystallogr. 2003, 36, 7-13.

53. Macrae, C.F.; Edgington, P.R.; McCabe, P.; Pidcock, E.; Shields, G.P.; Taylor, R.; Towler, M.; van de Streek, J. Mercury: Visualization and analysis of crystal structures. J. Appl. Crystallogr. 2006, 39, 453-457.

(C) 2015 by the authors; licensee MDPI, Basel, Switzerland. This article is an open access article distributed under the terms and conditions of the Creative Commons Attribution license (http://creativecommons.org/licenses/by/4.0/). 